\title{
Termoquímica na perspectiva CTSA para o ensino de química por meio das TIC
}

\author{
Thermochemistry in the ESTS perspective for teaching chemistry through \\ ICT
}

\author{
Linney Chrissie Konno Piton Pereira (linneyckp@gmail.com) \\ Bacharel e Licenciada em Química, Mestranda em Ensino de Ciências da Natureza e Matemática, \\ UFMT/Sinop, ICNHS \\ Carmen Wobeto (carmenwobeto2014@gmail.com) \\ Professora Doutora do Programa de Pós-Graduação em Ensino de Ciências da Natureza e Matemática \\ (PPGECM) - UFMT, Sinop/MT
}

Felicio Guilardi Junior (fifo2801@gmail.com)

Professor Doutor do Programa de Pós-Graduação em Ensino de Ciências da Natureza e Matemática (PPGECM) - UFMT, Sinop/MT

Patrícia Rosinke (patirosinke@yahoo.com.br)

Professora Doutora do Programa de Pós-Graduação em Ensino de Ciências da Natureza e Matemática (PPGECM) - UFMT, Sinop/MT

Resumo: Esta pesquisa apresenta o desenvolvimento de uma proposta de ensino investigativo de termoquímica na perspectiva Ciência-Tecnologia-Sociedade-Ambiente (CTSA), cujo desenvolvimento se deu por meio das Tecnologias da Informação e Comunicação (TIC) em diversos canais de comunicação que viabilizaram a aprendizagem remota. Tais ferramentas digitais possibilitaram o ensino durante $\mathrm{o}$ isolamento social ocasionado pela pandemia COVID-19 e suspensão de atividades presenciais nas escolas. As aulas contaram com a participação de dois grupos de alunos matriculados no segundo ano do ensino médio de uma escola da rede estadual do município de Colíder, Mato Grosso. As atividades síncronas foram divididas em três momentos didáticos de duas horas cada, nas quais os participantes foram motivados ao questionamento visando a construção da argumentação crítica. Observamos a sensibilização quanto aos conceitos estudados de termoquímica associados as calorias, alimentação saudável e hábitos alimentares, com um olhar especial durante esse período de isolamento.

Palavras-chave: Ensino de química; Pandemia COVID-19; Tecnologias da Informação e Comunicação TIC.

Abstract: This research presents the development of an investigative teaching proposal
for thermochemistry in the Environment-Science-Technology-Society (ESTS)
perspective, whose development took place through Information and Communication
Technology (ICT) in several communication channels that made remote learning
feasible. Such digital tools enabled teaching during social isolation caused by the
pandemic COVID-19 and suspension of classroom activities in schools. The classes
were attended by two groups of students enrolled in the second year of High School at a

Recebido em: $27 / 08 / 2020$

Aceito em: $1 \% / 12 / 2020$ 
state school in the city of Colíder, Mato Grosso. The synchronous activities were divided into three didactic moments of two hours each, in which the participants were motivated to question in order to the construction of critical argumentation. We observed awareness of the studied concepts of thermochemistry associated with calories, healthy eating and eating habits, with a special look during this period of isolation.

Keywords: Chemistry teaching; Pandemic COVID-19; Information and Communication Technology ICT.

\section{INTRODUÇÃO}

No ano de 2020, toda a sociedade vivencia um novo momento, marcado por uma pandemia global, a qual vem adotando medidas e restrições para minimizar os efeitos da doença COVID-19, segundo Hallal et al. (2020) é classificada pela Organização Mundial de Saúde (OMS) como uma doença produzida pelo vírus denominado SARSCoV-2 e que se tornou uma emergência de saúde internacional.

Os países atingidos pela pandemia COVID-19 adotaram medidas de distanciamento social buscando minimizar a velocidade de transmissão da doença, segundo Aquino et al. (2020) tais medidas têm sido implementadas de modo gradual e distinto em cada país.

\footnotetext{
Muitos países implementaram uma série de intervenções para reduzir a transmissão do vírus e frear a rápida evolução da pandemia. Tais medidas incluem o isolamento de casos; o incentivo à higienização das mãos, à adoção de etiqueta respiratória e ao uso de máscaras faciais caseiras; e medidas progressivas de distanciamento social, com o fechamento de escolas e universidades, a proibição de eventos de massa e de aglomerações, a restrição de viagens e transportes públicos, a conscientização da população para que permaneça em casa, até a completa proibição da circulação nas ruas, exceto para a compra de alimentos e medicamentos ou a busca de assistência à saúde. Essas medidas têm sido implementadas de modo gradual e distinto nos diferentes países, com maior ou menor intensidade, e seus resultados, provavelmente, dependem de aspectos socioeconômicos, culturais, de características dos sistemas políticos e de saúde, bem como dos procedimentos operacionais na sua implementação. (AQUINO et al., 2020, p. 2424).
}

Tudo mudou! No Brasil não foi diferente, os trabalhos, os estudos e a convivência (social e familiar) passaram a ser remotos. Diversas medidas de distanciamento foram adotadas, dentre elas à suspensão das atividades presenciais nas escolas.

O estado de Mato Grosso, localizado na Região Centro-Oeste, publicou diversos decretos relacionados à suspensão das atividades presenciais nas escolas, dentre eles

Recebido em: $27 / 08 / 2020$

Aceito em: $1 \% / 12 / 2020$ 
destacamos: o "Decreto No 407, de março de 2020 no Capítulo III, Art. 9, dispõe sobre a suspensão das atividades escolares de todas as redes de ensino" (MATO GROSSO, 2020) e o "Decreto $N^{\circ} 510$, de 03 de junho de 2020 mantém a suspensão das aulas presenciais. Ainda não existe previsão para o retorno presencial, mas espera-se que este retorno aconteça de forma remota" (MATO GROSSO, 2020).

Com a suspensão das aulas e planejamentos em andamento, permaneceu o anseio de manter o contato, o aprendizado e o ensino de química com os alunos, mesmo remotamente. Dessa maneira, foram realizadas algumas mudanças na metodologia de aplicação desta pesquisa, como a inserção das TIC. Para o desenvolvimento, contamos com a participação de alunos do $2^{\circ}$ ano do ensino médio (dos quais sou professora de química) pertencentes a uma escola estadual no município de Colíder, no estado de Mato Grosso, que participarem voluntariamente da pesquisa.

Acreditamos na possibilidade das TIC, auxiliarem na contextualização da química que está a nossa volta. Neste sentido, elaboramos a presente pesquisa abordando a temática caloria dos alimentos, associada aos conceitos termoquímicos na perspectiva CTSA por meio das TIC procurando viabilizar reflexões críticas durante esse período de isolamento social.

Sendo assim, esta pesquisa contou com as etapas: (1) convidar alunos do $2^{\circ}$ ano do ensino médio, para estudos sobre a termoquímica por meio das TIC; (2) explorar na perspectiva CTSA a aprendizagem da termoquímica voltada as calorias dos alimentos; (3) realizar a comunicação e interação de aulas remotas e atividades por meio das TIC; (4) analisar a percepção dos alunos a respeito da termoquímica, voltada as calorias dos alimentos relacionadas à saúde, ao ambiente e ao momento em que vivemos a pandemia COVID-19.

\section{REFERENCIAL TEÓRICO}

\subsection{A EDUCAÇÃO POR MEIO DAS TIC}

A Base Nacional Comum Curricular - BNCC, na etapa Ensino Médio, garante aprendizagens para a tomada de decisões e o enfrentamento dos novos desafios contemporâneos, dentre elas, o documento traz como foco o "[...] reconhecimento das potencialidades das tecnologias digitais para a realização de uma série de atividades

Recebido em: $27 / 08 / 2020$

Aceito em: $1 \% / 12 / 2020$ 
relacionadas a todas as áreas do conhecimento" (BRASIL, 2018, p. 474). Evidenciamos

a importância de destacar as competências e habilidades que as tecnologias digitais

podem permitir aos estudantes no decorrer do processo de ensino e aprendizagem:

[...] buscar dados e informações de forma crítica nas diferentes mídias, inclusive as sociais, analisando as vantagens do uso e da evolução da tecnologia na sociedade atual, como também seus riscos potenciais; apropriar-se das linguagens da cultura digital, dos novos letramentos e dos multiletramentos para explorar e produzir conteúdo em diversas mídias, ampliando as possibilidades de acesso à ciência, à tecnologia, à cultura e ao trabalho; usar diversas ferramentas de software e aplicativos para compreender e produzir conteúdo em diversas mídias, simular fenômenos e processos das diferentes áreas do conhecimento, e elaborar e explorar diversos registros de representação matemática; e utilizar, propor e/ou implementar soluções (processos e produtos) envolvendo diferentes tecnologias, para identificar, analisar, modelar e solucionar problemas complexos em diversas áreas da vida cotidiana, explorando de forma efetiva o raciocínio lógico, o pensamento computacional, o espírito de investigação e a criatividade. (BRASIL, 2018, p. 474-475)

As TIC constituem uma gama de ferramentas que possibilitam compartilhar, distribuir e reunir informações, por meio de um conjunto tecnológico formado por web sites, internet, revistas, livros que constituem canais de acesso (DOURADO et al., 2014). A presença das TIC pode "amplificar e potencializar os processos de ensino e aprendizagem dentro e fora de sala de aula" (SULZBACHER, 2019, p. 257).

Atualmente, estas tecnologias vêm se tornando essenciais em diversos setores e a educação é um deles. Dourado et al. (2014) retrata como elas vem sendo aplicadas:

\footnotetext{
Na atualidade, a tecnologia está sendo aplicada cada vez mais intensamente nas mais diversas áreas da sociedade e, com esse desenvolvimento, as tecnologias de informação e comunicação - TIC - estão provocando uma série de mudanças na vida das pessoas em um curto espaço de tempo. Assim, a educação, por estar inserida nessa sociedade, também está passando por essas transformações quanto às relações de ensino no que tange às práticas dos professores e às formas de aprendizagem dos estudantes (DOURADO et al., (2014) p.357).
}

Cabe ao professor escolher a melhor maneira de utilizar as TIC em benefício das novas aprendizagens. "Para que as TIC sejam utilizadas com êxito para além de meros adornos, o professor precisa ter o entendimento de que estes instrumentos englobam um conjunto de conhecimentos tecnológicos que requerem apropriação para articulação" (MARIN et al., 2019, p.5). A utilização correta das TIC nas aulas, segundo Osório et al. (2019) valorizam os estudantes, considerando seus saberes prévios, atrelados a uma pedagogia bem estruturada e somam no aprendizado significativo dos estudantes.

Recebido em: $27 / 08 / 2020$

Aceito em: $1 \% / 12 / 2020$ 
Essas ferramentas tecnológicas podem viabilizar o ensino por meio de sua aplicação, porém muitos profissionais ainda não se sentem capacitados para realizar esse processo de inserção. "A construção de conhecimentos apropriados à utilização das Tecnologias de Informação e Comunicação (TIC) para fins educativos apresenta-se como uma nova barreira a ser superada pelos professores" (SCHUHMACHER et al., 2017, p. 564). Este estudo torna-se uma alternativa de inserção das TIC no planejamento de ensino de química. Vale ressaltar a necessidade de publicações de pesquisas e relatos de ensino com esses recursos, tendo em vista auxiliar na ruptura das barreiras da prática docente mencionada por Schumacher et al.

\subsection{A PERSPECTIVA CTSA NO ENSINO QUÍMICA}

A perspectiva Ciência-Tecnologia-Sociedade-Ambiente (CTSA) vem se destacando em relação ao movimento CTS (Ciência-Tecnologia-Sociedade) pelo enfoque das questões ambientais, segundo Santos (2012):

Apesar de a educação CTS incorporar implicitamente os objetivos da educação ambiental, pois o movimento CTS surgiu com uma forte crítica ao modelo desenvolvimentista que estava agravando a crise ambiental e ampliando o processo de exclusão social, vários autores têm adotado a denominação CTSA com o propósito de destacar o compromisso da educação CTS com a perspectiva socioambiental. (SANTOS, 2012, p. 53)

As aprendizagens na perspectiva CTSA também consideram aprendizagens coletivas e acentuadas, segundo Santos e Mortimer (2002) vinculam a abordagem educacional à interesses coletivos como fraternidade, solidariedade, respeito ao próximo e consideram relevantes as discussões sobre de temas locais, de políticas públicas ou globais.

Acreditamos que a abordagem na perspectiva CTSA evidencia a formação do pensamento crítico em relação as nossas ações no meio social. Segundo Santos (2007), a perspectiva CTSA busca a ênfase curricular no ensino de ciências e propõe destacar as mudanças em função dos contextos sócio-históricos, como também os ambientais.

O ensino de química contextualizado deveria seguir a perspectiva CTSA, pois possibilita a integração entre o conhecimento específico e as questões problemáticas relacionadas a temas de interesses dos alunos e da sociedade (AKAHOSHI, 2012).

Recebido em: $27 / 08 / 2020$

Aceito em: $1 \% / 12 / 2020$ 
Nesta pesquisa, buscamos o ensino de química na perspectiva CTSA, com enfoque voltado à aproximação dos conteúdos com a realidade social e ambiental do aluno. "Torna-se necessário o desenvolvimento de conceitos, temas e conteúdos articulados com o cotidiano dos estudantes, pois a aprendizagem e o processo de construção do conhecimento estão interligados” (OSÓRIO et al., 2019, p.23).

\subsection{A NATUREZA DA INVESTIGAÇÃO}

A natureza desta pesquisa caracteriza-se como qualitativa descritiva, cujas características são descritas por Bodgan e Biklen (1994) do seguinte modo: 1) o ambiente natural como fonte dos dados e o pesquisador como principal instrumento; 2) os dados analisados devem conter toda a essência e devem ser registrados com precisão; 3) o processo é o mais importante; 4) os dados devem ser analisados de forma indutiva; 5) o pesquisador deve se importar com os significados de seus dados.

Ludke e André (1986) destacam que nesse tipo de pesquisa deve ser considerado o ambiente natural como fonte direta de dados e o pesquisador como o principal instrumento.

Os dados coletados durante a pesquisa foram interpretados e analisados por análise de conteúdo, segundo Moraes (1999) caracteriza-se como uma busca teórica e prática, constituindo-se bem mais do que uma simples técnica de análise de dados, mas representando uma abordagem metodológica com características e possibilidades próprias.

\section{METODOLOGIA}

A pesquisa contou com pesquisa bibliográfica que possibilitou as reflexões e entendimentos sobre o tema estudado. Realizamos uma abordagem qualitativa descritiva com análise de conteúdo para descrição dos dados.

Esta pesquisa ocorreu no mês de julho de 2020, durante o período de suspensão das aulas presenciais, como medidas de isolamento social. Diante de tantas mudanças e adaptações, procuramos manter o contato com os alunos e estimular a busca pelo conhecimento e a aprendizagem de química, mesmo em situações adversas. Acreditamos que como seres humanos somos capazes de nos adaptarmos as necessidades de facilitar o ensino com o uso das TIC.

Recebido em: $27 / 08 / 2020$

Aceito em: $1 \% / 12 / 2020$ 
Permeando este pensamento e sendo professora de química regente em uma escola rede estadual, fizemos o convite a um grupo de alunos, os quais tivessem disposição e disponibilidades para novas aprendizagens e colaboração com esta pesquisa.

As atividades realizadas foram desenvolvidas com dois grupos de alunos do $2^{\circ}$ ano do ensino médio de uma escola estadual, situada na zona urbana, no centro da cidade de Colíder, estado de Mato Grosso. A referida escola funciona nos três períodos, oferecendo a modalidade de ensino médio regular.

Enfatizamos que todos os contatos, aulas e atividades ocorreram de forma remota por meio TIC. Os canais que viabilizaram o desenvolvimento da aprendizagem e da comunicação foram: WhatsApp, App Desrotulando, e-mails, Google Forms, plataforma Jitsi Meet, por meio do notebook ou aparelho de celular.

Os grupos desenvolveram as mesmas atividades de modo síncrono nos Momentos Didáticos (MD) em dois horários diferentes, sendo: matutino das $8 \mathrm{~h}$ às $10 \mathrm{~h}$ e vespertino das $14 \mathrm{~h}$ às $16 \mathrm{~h}$, por meio da plataforma Jitsi Meet, onde ocorreram as interações, contribuições e as reflexões com as falas dos alunos participantes. Além de outros MD que ocorreram de modo assíncrono pelo WhatsApp, e-mails e Google Forms, os quais os alunos enviaram os questionamentos, as dúvidas ou as atividades para casa, que foram desenvolvidas.

As aulas aconteceram em três MD. Cada aula pode ser chamada de "momento", pois caracteriza os momentos de estudos para produção da análise do percurso organizado na pesquisa, segundo Chevallard (1999). O referido autor descreve tal organização como sendo:

\begin{abstract}
A noção de momento não remete mais do que na aparência à estrutura temporária do processo de estudo. Um momento, no sentido dado à palavra aqui, é primeiramente uma dimensão em um espaço multidimensional, um fator em um processo multifatorial. Bem entendido, uma gestão saudável do estudo exige que cada um dos momentos didáticos seja realizado no momento certo, ou mais exatamente, nos bons momentos: por um momento de estudo geralmente é realizado várias vezes, sob a forma de uma multiplicidade de episódios que brotam no tempo. (CHEVALLARD, 1999, p.21)
\end{abstract}

Nos Momentos Didáticos buscamos explorar a perspectiva CTSA de forma investigativa, procurando construir os conceitos iniciais da aprendizagem de Termoquímica voltada as calorias dos alimentos.

Recebido em: $27 / 08 / 2020$

Aceito em: $1 \% / 12 / 2020$ 
Neste contexto, viabilizamos desenvolver o conteúdo de Termoquímica, pois pertence ao currículo do $2^{\circ}$ ano do ensino médio. A temática associada a caloria dos alimentos aproxima os conceitos químicos as situações cotidianas, dessa forma o aluno percebe que a química está presente no seu dia a dia, o que pode contribuir para mudanças de hábitos alimentares e suas observações como consumidor. A proposta compreendeu a percepção dos conceitos físico-químicos da termoquímica associados aos seus efeitos na saúde do homem e que podem estar presentes nos alimentos.

Procuramos construir reflexões e pensamentos críticos sobre conceitos termoquímicos, por meio da identificação de informações contidas nos rótulos de alimentos e o consumo saudável de alimentos. Os três Momentos Didáticos sobre os estudos de Termoquímica com seus respectivos conteúdos, objetivos, problemáticas, recursos didáticos e atividades desenvolvidas estão organizados no Quadro 1.

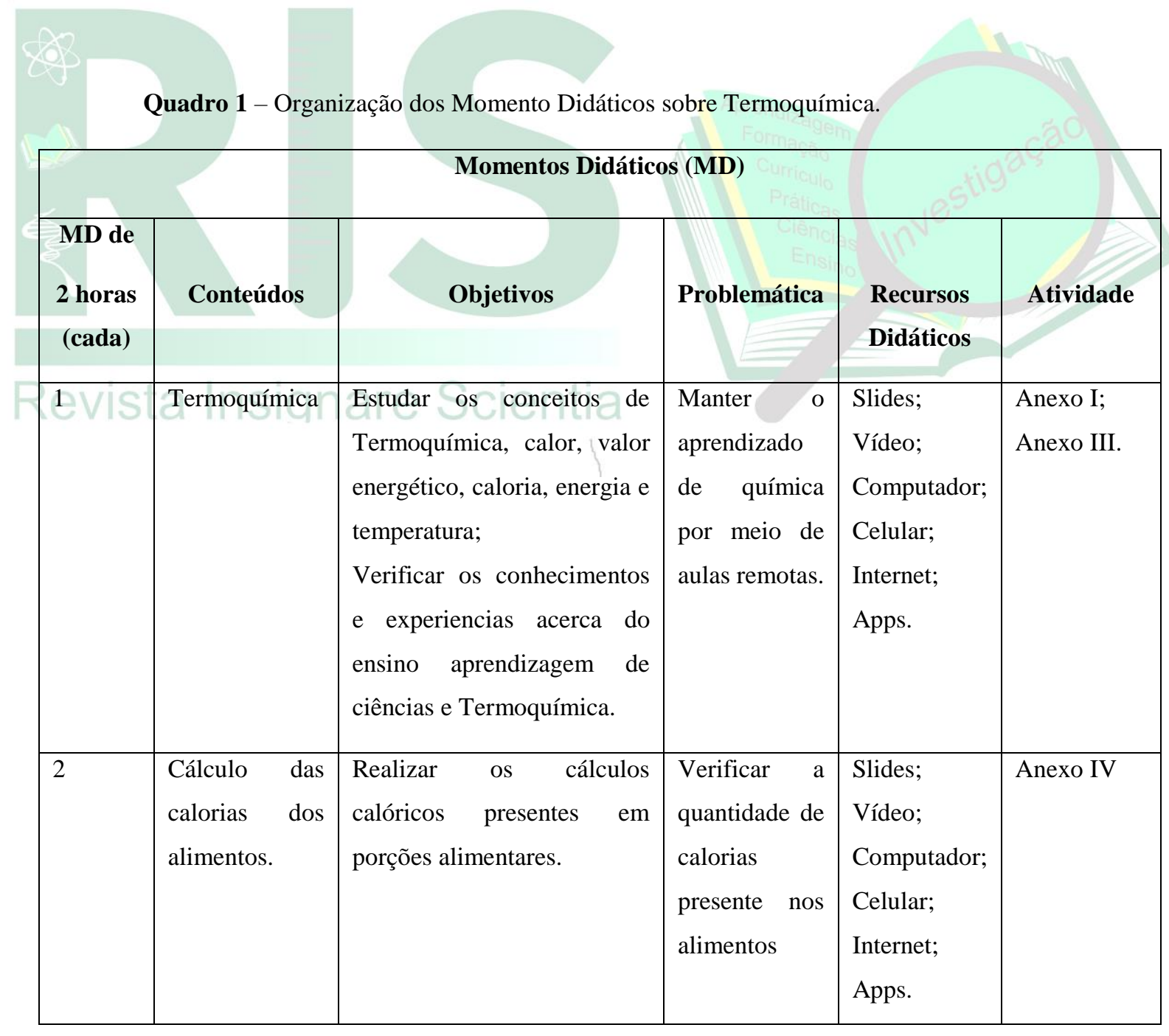




\begin{tabular}{|c|c|c|c|c|c|}
\hline 3 & $\begin{array}{l}\text { Diário } \\
\text { alimentar; } \\
\text { Alimentação } \\
\text { saudável e } \\
\text { Saúde. }\end{array}$ & $\begin{array}{l}\text { Refletir sobre os hábitos } \\
\text { alimentares; } \\
\text { Desenvolver o pensamento } \\
\text { crítico relacionados a } \\
\text { alimentação saudável. }\end{array}$ & $\begin{array}{l}\text { Compreender } \\
\text { a importância } \\
\text { de uma } \\
\text { alimentação; } \\
\text { Relacionar } \\
\text { alimentação } \\
\text { saudável com } \\
\text { benefícios a } \\
\text { saúde. }\end{array}$ & $\begin{array}{l}\text { Slides; } \\
\text { Vídeo; } \\
\text { Computador; } \\
\text { Celular; } \\
\text { Internet; } \\
\text { Apps. }\end{array}$ & Anexo II \\
\hline
\end{tabular}

Fonte: elaborado pelos autores

\section{RESULTADOS E DISCUSSÃO}

Para interpretação das respostas dos alunos participantes e manter seu anonimato, eles foram descritos por meio das letras de $\mathrm{A}$ à $\mathrm{J}$. $\mathrm{O}$ grupo vespertino teve uma aluna $\mathrm{p}$ que não participou nos MD 2 e 3, sua ausência foi justificada por problemas de saúde com familiares.

Podemos destacar que as TIC selecionadas viabilizaram os MD, a interação, a participação e o retorno dos alunos. Durante o processo tivemos alguns momentos de oscilação do sinal de internet, porém todos foram ajustados e os MD não foram prejudicados.

\subsection{APRESENTAÇÃO DOS DADOS}

\subsubsection{MOMENTO DIDÁTICO 1 - QUESTIONÁRIO PRÉVIO}

No primeiro MD síncrono, foi enviado aos alunos por meio do Google Forms o questionário prévio (Anexo I). O tempo observado para os alunos responderem e enviarem foi de cerca de 30 minutos. Os dados obtidos estão descritos no Quadro 2.

Quadro 2- questionário prévio.

\begin{tabular}{|l|l|}
\hline \multicolumn{1}{|l|}{ PERGUNTAS } & \multicolumn{1}{|c|}{ RESPOSTAS DOS ALUNOS } \\
\hline $\begin{array}{l}\text { 1. Onde você } \\
\text { observa a Ciência } \\
\text { na sua vida? Cite } \\
\text { exemplos } \\
\text { explique. }\end{array}$ & $\begin{array}{l}\text { A- Na cozinha ao preparar alguma refeição. } \\
\text { B- A ciência está presente em várias atividades do nosso dia a dia, como } \\
\text { plantar uma árvore você está ajudando em um campo da ciência que ajudará a } \\
\text { preservar o meio ambiente, ao esquentar uma água você está praticando a } \\
\text { convecção térmica que envolve a física, não jogando bateria em lugares impróprios } \\
\text { por conta de reagentes químicos poluentes. }\end{array}$ \\
\hline
\end{tabular}

Recebido em: $27 / 08 / 2020$

Aceito em: $1 \% / 12 / 2020$ 


\begin{tabular}{|c|c|}
\hline & $\begin{array}{l}\text { C- Em todos os lugares. Em uma flor, na terra, na água, nos ingredientes } \\
\text { de uma receita etc. } \\
\text { D- No dia a dia, nas paisagens, nas temperaturas como frio ou calor. } \\
\text { E- No banheiro, quando usamos produtos de químicos para tirar o mau } \\
\text { cheiro, no ar condicionado que refrigera o ambiente através de reações físicas etc. } \\
\text { F- Em todos os lugares em que praticamos qualquer atividade, como: } \\
\text { ferver uma água ou leite, cozinhar algo, percorrer uma distância a uma certa } \\
\text { variação do tempo, diluir algo na água, e em uma aula experimental de ciência. }\end{array}$ \\
\hline $\begin{array}{l}\text { 2. Na sua opinião } \\
\text { a Escola ajuda a } \\
\text { compreender a } \\
\text { vida e a Ciência. }\end{array}$ & $\begin{array}{l}\text { A- Mais ou menos, deveria acontecer de uma forma mais clara e com mais } \\
\text { frequência. } \\
\text { B-Sim. } \\
\text { C- Com certeza. } \\
\text { D- Sim, como cada detalhe tem uma explicação, as reações de cada ser ou } \\
\text { fenômenos que muitas vezes passam despercebidos por nós. } \\
\text { E- Sim, porém a maior parte depende do esforço do aluno de ir atrás } \\
\text { desses entendimentos. } \\
\text { I- Sim, a escola nos ajuda a conhecer e aprender melhor sobre a vida e } \\
\text { ciência. }\end{array}$ \\
\hline $\begin{array}{l}\text { 3. Os estudos na } \\
\text { Escola mudaram } \\
\text { a sua forma de } \\
\text { ver o mundo a } \\
\text { sua volta. } \\
\text { Exemplifique. }\end{array}$ & $\begin{array}{l}\text { A- Sim, pois me ajudaram a entender vários conceitos sobre diferentes } \\
\text { matérias escolares. } \\
\text { C- Sim, aprendi muitas coisas que não sabia, ou que eu achava que sabia, } \\
\text { mas na verdade existem muitas explicações para tudo, como por exemplo a maneira } \\
\text { como funciona o nosso corpo, a mudança de uma flor, etc. } \\
\text { Si O D- Sim, como por exemplo em uma receita, cada ingrediente tem que ter } \\
\text { uma quantidade x para dar certo, ou a temperatura tem que estar adequada para que } \\
\text { não altere toda a receita. } \\
\text { E- Mais ou menos, foi através deles que eu desenvolvi o interesse e a } \\
\text { curiosidade para ir atrás desse entendimento. } \\
\text { I- Sim, a escola nos faz ver o mundo de forma mais científica para } \\
\text { prestarmos atenção a pequenas transformações do nosso dia a dia. }\end{array}$ \\
\hline $\begin{array}{l}\text { 4. Nas aulas de } \\
\text { Ciências/Química } \\
\text { você realizou } \\
\text { atividades } \\
\text { experimentais ou } \\
\text { lúdicas? Quais? }\end{array}$ & $\begin{array}{l}\text { A-Sim. Identificação de fases de uma mistura, instrumentos para fazer } \\
\text { separação de uma mistura, dinâmicas com tabela periódica e ligações químicas. } \\
\text { C-Sim. Atividades no laboratório e jogos na sala de aula. } \\
\text { F- Sim, para identificarmos as reações em suas fases, a distribuição } \\
\text { eletrônica, tipos de ligação. } \\
\text { G- Sim. Distribuição de elétrons em camadas, atividades demonstrativas } \\
\text { de misturas heterogênea e homogênea e montamos moléculas. } \\
\text { J - Lúdicas, com um jogo de ligação iônica. }\end{array}$ \\
\hline
\end{tabular}




\begin{tabular}{|c|c|}
\hline $\begin{array}{l}\text { 5. Diferencie } \\
\text { calor, caloria e } \\
\text { energia. }\end{array}$ & $\begin{array}{l}\text { A- Calor: energia para trocas de calor entre corpos; } \\
\text { C- Temperatura recebida por um corpo; energia em forma de calor/ caloria } \\
\text { que algum produto tem; é uma produção ou ação que se manifesta de várias formas } \\
\text { como na eletricidade } \\
\text { E- Caloria é uma unidade de medida de energia, calor é a energia térmica } \\
\text { transmitida de um corpo para o outro, e a energia é usada para realizar alguma } \\
\text { reação ou trabalho. } \\
\text { H- Calor é uma grandeza que mede a sensação térmica, caloria é } \\
\text { quantidade de algo, energia é quando algo produz energia para se fazer um } \\
\text { determinado trabalho. } \\
\text { I- Calor é temperatura alta Caloria é quantidade de calor de um alimento? } \\
\text { Energia é tudo que modifica matéria. } \\
\text { J- Bem, caloria é a quantidade de energia necessária para elevar a um grau } \\
\text { célsius a temperatura de um grama de água numa pressão de 1atm Calor específico } \\
\text { é uma grandeza física que mede a variação térmica de certa substância ao receber } \\
\text { determinada quantidade de calor. Calor é a energia térmica transferida entre dois } \\
\text { corpos que estão a temperaturas diferentes. }\end{array}$ \\
\hline $\begin{array}{l}\text { 6. O que é cal, } \\
\text { Kcal, J, KJ? }\end{array}$ & $\begin{array}{l}\text { A- Calorias, Quilocalorias, Joules e Quilo joule. } \\
\text { D - São os valores nutricionais de cada alimento. } \\
\text { E- Cal = caloria, uma unidade de medida de energia Kcal = quilo caloria, } \\
\text { equivale a } 1000 \text { calorias J = joule, unidade de medida de trabalho, portanto pode ser } \\
\text { convertida para caloria. } \\
\text { G - Uma unidade de medida presente nos alimentos. } \\
\text { H - São unidades de medidas. } \\
\text { J - J(Joule) é a unidade SI de energia, Cal (Caloria é uma quantização } \\
\text { normalmente usada em química e térmica. }\end{array}$ \\
\hline $\begin{array}{l}\text { 7. O alimento } \\
\text { tem energia ou } \\
\text { caloria? } \\
\text { Justifique. }\end{array}$ & $\begin{array}{l}\text { A- Caloria e energia, cada alimento possui valor energético e calorias; } \\
\text { D- As duas, pois a Caloria é uma unidade de medida para descobrir a } \\
\text { energia presente em cada nutriente de um alimento. } \\
\text { E - Energia, e essa energia é medida em calorias. } \\
\text { F - Calorias, pois ele não realiza trabalho, e sim pode uma reação química. } \\
\text { H- Eles têm energia para nos deixar de pé, pois caloria é a medida. } \\
\text { I- Caloria. }\end{array}$ \\
\hline
\end{tabular}

Fonte: elaborado pelos autores

Observamos que os alunos apresentavam conhecimento prévio sobre a importância da ciência e que ela está presente em seu dia a dia, pois a maior parte dos alunos: A, C, F, G H e J fizeram essa relação e associaram aos alimentos. Entende-se 
que "o conhecimento químico é necessário para que o cidadão possa agir frente a múltiplos eventos do contexto em que se encontra inserido, podendo modificar seu entorno" (ZANOTTO et al., 2016, p. 728).

Destacamos a primeira indagação do questionário prévio "Onde você observa a Ciência na sua vida? Cite exemplos e explique”, pois pretendíamos entender como os alunos compreendiam e observavam a ciência em suas vidas. Dentre as respostas evidenciamos o aluno G "[...] no dia a dia, por exemplo: ao preparar uma mistura de bolo, no processo de fermentação do bolo" e o aluno I "[...] a ciência está em todo o lugar, desde uma pequena transformação como a água de líquido-sólido-gasoso do nosso dia a dia, tanto como nosso cotidiano, precisamos da ciência”. É possível dizer que as escritas dos alunos apontam a percepção da ciência em suas vidas.

Nas respostas da segunda questão "Na sua opinião a Escola ajuda a compreender a vida e a Ciência”, buscamos reflexões dos alunos quanto a ajuda da Escola na compreensão da vida e da Ciência. Dentre elas, realçamos o aluno D “[...] sim, como cada detalhe tem uma explicação, as reações de cada ser ou fenômenos que muitas vezes passam despercebidos por nós.” e o aluno I “[...] sim, a escola nos ajuda a conhecer e aprender melhor sobre a vida e ciência". Com base nos dados coletados, é possível perceber que os alunos entendem a escola com auxiliadora na compressão da ciência e da vida.

\subsubsection{MOMENTO DIDÁTICO 2 - INVESTIGAR AS EMBALGENS DOS}

\section{ALIMENTOS}

A atividade do MD 2 foi enviada para os alunos desenvolverem em casa (Anexo III). Para desenvolvê-la, eles tiveram que realizar uma investigação nas embalagens de alimentos buscando identificar e compreender o valor energético, as calorias e a unidade de medida contida nas embalagens de alimentos escolhidos. Dentre as respostas recebidas, destacamos e apresentamos a escrita do aluno $\mathbf{E}$ por meio da tabela 1.

Tabela 1 - Respostas do aluno E, referente a atividade para casa da aula 1.

\section{Atividade Aula 1 - Aluno E}

\section{Pergunta}

Resposta

Recebido em: 27/08/2020

Aceito em: $1 \% / 12 / 2020$ 
1. Observe nos rótulos escolhidos se está escrito: "valor energético", qual o significado dessa expressão?
É a quantidade de energia que o alimento tem medido em calorias
2. O que significa $\mathrm{KJ}$ e Kcal? Elas têm alguma relação? Qual?
KJ = Quilo joule; Kcal=Quilocaloria; Ambos são unidades de medida para energia, sendo que KJ equivale a $1000 \mathrm{~J}$ e Kcal equivale a $1000 \mathrm{cal}$, sabendo que $1 \mathrm{cal}=4,183 \mathrm{~J}$, podemos converter Kcal para KJ multiplicando por 4,183

3. O que são calorias?

Elas medem a quantidade de energia (calor), 1 caloria é contém energia necessária para elevar a temperatura de $1 \mathrm{~g}$ de água em 1C

4. O termo valor energético e calorias contido nos rótulos tem o mesmo significado?
$\mathrm{O}$ valor energético é a quantidade de energia presente em um alimento, e as calorias são a unidade de medida para esse valor
Coca-Cola, uma porção de $220 \mathrm{ml}$ contém $94 \mathrm{kcal}$; Açaí, uma porção de $50 \mathrm{~g}$ contém $63 \mathrm{kcal}$; Pipoca, uma porção de $25 \mathrm{~g}$ contém $82 \mathrm{kcal}$. energético que ele contém por porção (1)

6.Observe no final de cada rótulo o texto escrito em letras minúsculas e responda: o que significa "Valores diários de referência" e "necessidades energéticas"?
Valores diários de referência é a quantidade de calorias necessárias que uma pessoa adulta saudável precisa por dia em média. Necessidades energéticas é o quanto que uma pessoa precisa para se manter durante o dia de acordo com a atividade que ela realiza, sua altura, peso etc.

\section{Fonte: elaborada pelos autores.}

Percebemos na escrita do aluno $\mathbf{E}$ que suas respostas foram elaboradas com argumentação e significados, retratando que o mesmo, utilizou-se de investigação, pesquisa e exploração dos conceitos presentes das perguntas.

\subsubsection{MOMENTO DIDÁTICO 3 - DIÁRIO ALIMENTAR}

A atividade Diário Alimentar (Anexo IV) foi desenvolvida em casa. As respostas retratam a compreensão do objetivo, pois contém os dados de valor calórico e cálculos da energia contida nas porções alimentares. As respostas dos alunos B e C estão representadas respectivamente pelas Figuras 1 e 2.

Recebido em: $27 / 08 / 2020$

Aceito em: $1 \% / 12 / 2020$ 


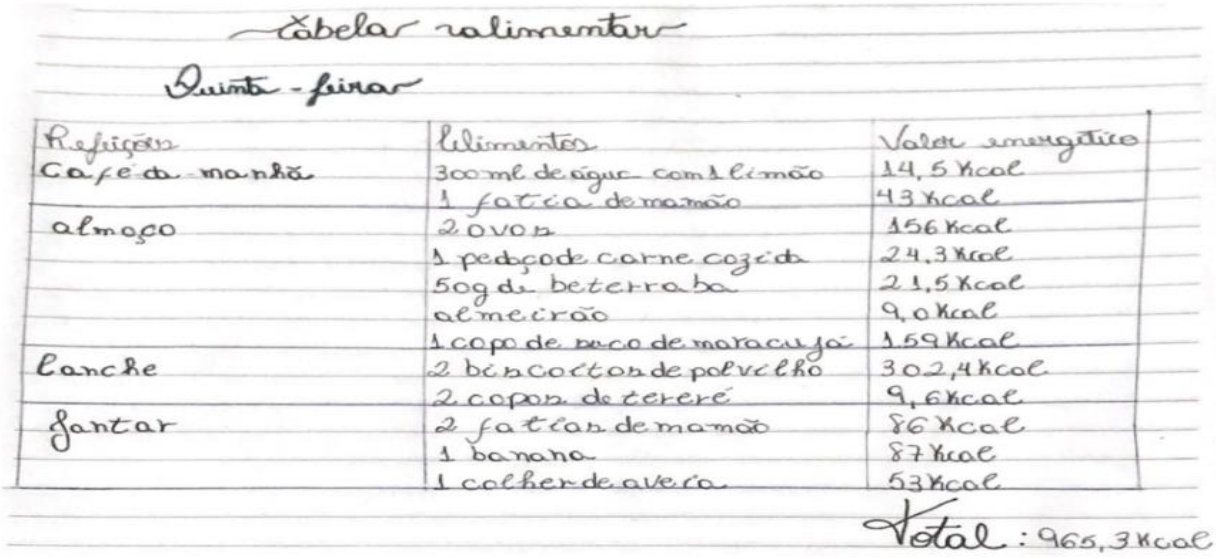

Figura 1 - Respostas escaneada do caderno do aluno B, referente a Atividade Diário Alimentar. Fonte: elaborada pelos autores.

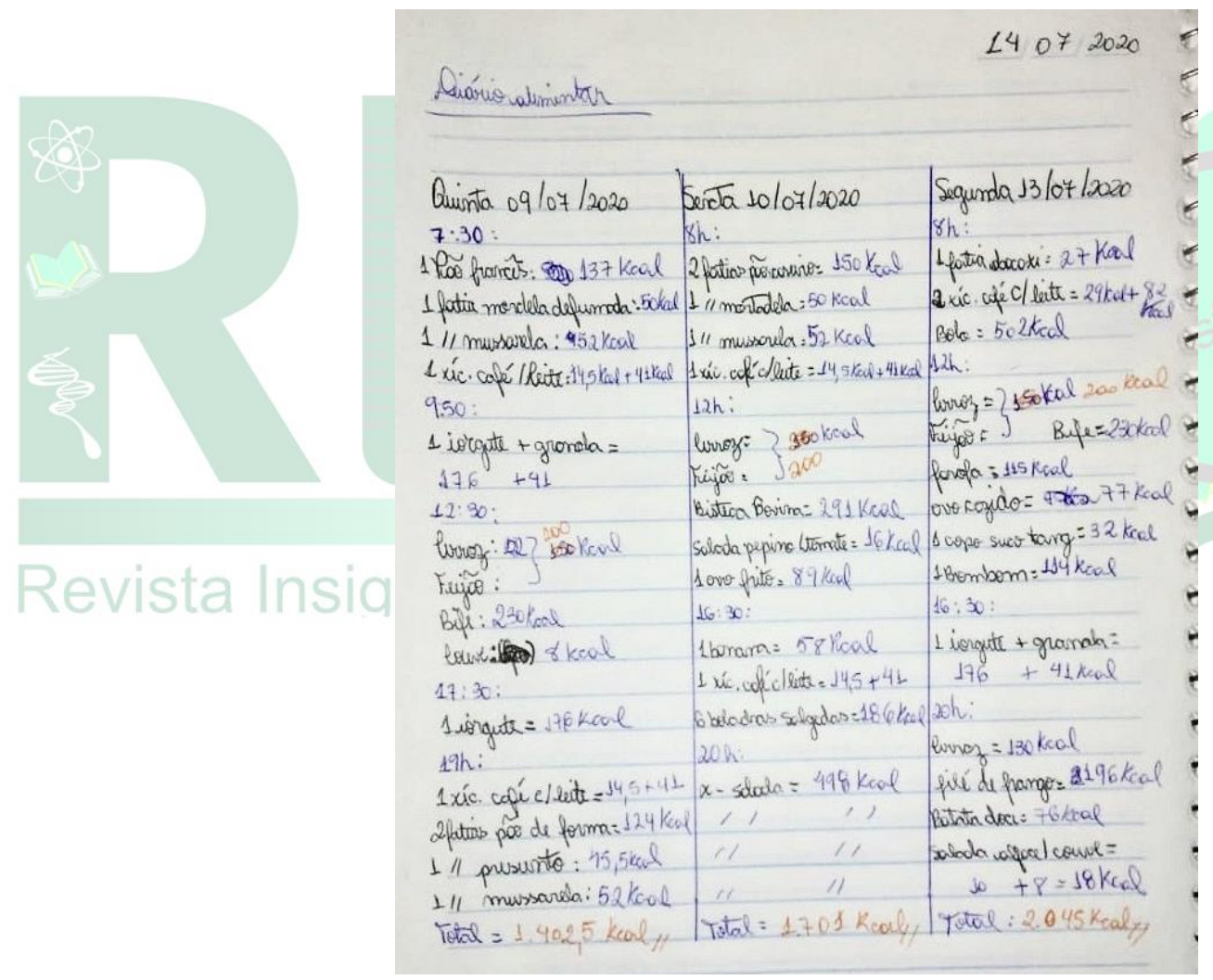

Figura 2 - Respostas escaneada do caderno do aluno C, referente a Atividade Diário Alimentar. Fonte: elaborada pelos autores.

As Figuras 1 e 2 permitem nos inferir que a aprendizagem remota foi desenvolvida nos momentos síncronos por meio dos MD, pois os diálogos e debates foram enriquecedores e permitiram o enfoque CTSA no decorrer da construção da atividade diário alimentar apresentados pelos alunos $\mathrm{B}$ e $\mathrm{C}$, os quais de forma 
investigativa calcularam os respectivos valores calóricos consumidos por porção alimentar em cada refeição que fizeram durante três dias.

\subsubsection{QUESTIONÁRIO APÓS ATIVIDADE}

No final do terceiro MD os alunos responderam o questionário após as atividades (Anexo II), com o objetivo de verificar se houve mudanças nas percepções e atitudes dos alunos, assim como evoluções na compreensão de conceitos de termoquímica. As respostas foram bem diversificadas, podemos observar apontamentos na perspectiva CTSA e estão apresentadas no Quadro 3.

Quadro 3 - Respostas dos Alunos referente Questionário Após as atividades.

\begin{tabular}{|c|c|}
\hline PERGUNTAS & RESPOSTAS DOS ALUNOS \\
\hline $\begin{array}{l}\text { 1. Responda sobre } \\
\text { a atividade } \\
\text { realizada: } \\
\text { A) Qual foi o } \\
\text { assunto? }\end{array}$ & $\begin{array}{l}\text { B- Caloria dos alimentos; } \\
\text { C- Diário alimentar, macronutrientes, eletroquímica, calorias. } \\
\text { D- Diário Alimentar. } \\
\text { E- Valor energético dos alimentos. } \\
\text { F- Termoquímica Caloria, Energia, unidade de medidas de Energias, } \\
\text { caloria e propriedades dos alimentos. } \\
\text { I- Fizemos uma atividade sobre alimentação onde anotamos nossa } \\
\text { alimentação durante } 3 \text { dias e fizemos o cálculo das calorias. }\end{array}$ \\
\hline $\begin{array}{l}\text { B) O que você ou } \\
\text { seu grupo fez? }\end{array}$ & $\begin{array}{l}\text { A- Todos nós fizemos um diário alimentar durante } 3 \text { dias, tivemos que } \\
\text { calcular as calorias de cada refeição e somar quantas calorias totais consumimos } \\
\text { durante o dia. } \\
\text { B- Debates e cálculos relacionados as calorias que consumimos; } \\
\text { D- Separamos e analisamos os nutrientes de cada alimento ingeridos. } \\
\text { G- Respondemos algumas questões, tiramos dúvidas e desenvolvemos } \\
\text { uma atividade anotando os alimentos que comemos com os seus valores calóricos. }\end{array}$ \\
\hline $\begin{array}{l}\text { C) O que você } \\
\text { aprendeu? }\end{array}$ & $\begin{array}{l}\text { B- Como calcular as calorias e suas proporções, que podemos sim ter uma } \\
\text { alimentação saudável sem gastar muito apenas sabendo dividir o que se deve } \\
\text { consumir em maior quantidade é menor; } \\
\text { H- Aprendi sobre a termoquímica dos alimentos, dicas de uma } \\
\text { alimentação mais saudável, aprendi a calcular a caloria doa alimentos que como, } \\
\text { consegui entender como os rótulos funcionam e aprendi mais sobre vários } \\
\text { alimentos que eu uso diariamente }\end{array}$ \\
\hline
\end{tabular}

Recebido em: $27 / 08 / 2020$

Aceito em: $1 \% / 12 / 2020$ 
D) Estas atividades que você realizou contribuíram para você mudar sua opinião ou forma de compreender as coisas a sua volta? Explique.
A- Sim, sempre tive uma alimentação não muito saudável, por conta de não gostar de certos alimentos. As aulas que tivemos me fez refletir sobre meus hábitos alimentares, além de aprender química com a nossa rotina;

C- Compreender as coisas a minha volta.

D- Sim, pois cada alimento contribui para alguma função no corpo, ou até mesmo valorizar o que temos em casa.

E- Sim, eu aprendi que eu devo me alimentar melhor.

F- Sim, O que é energia e o quando realmente cada alimentos tem de calorias.

I- Sim, mudou meu jeito de compreender as coisas em relação a temperatura, e como funciona em nosso dia a dia e também a utilizar da forma correta o rótulo que vem em nossos alimentos.

2. Diferencie calor, caloria e energia. temperatura; Energia: capacidade de realizar trabalho.

D- Calor e calorias são medidas usadas para medir energia, já a energia é a quantidade de energia presente em cada alimento/objeto.

E- Calor é uma energia medida em calorias ou em joules, ela faz as moléculas se agitarem, energia é necessária para realizar qualquer atividade.

H- Caloria é uma unidade de medida, calor é o estado de algo quando aquecido, energia é a capacidade de algo como a energia do sol de produzir energia para acender uma luz, capacidade de produzir trabalho.

3. O que é cal, C- Cal: caloria; Kcal: quilocaloria; J: joule; KJ: quilo joule.

Kcal, J, KJ?

D- Unidades de medida de energia.

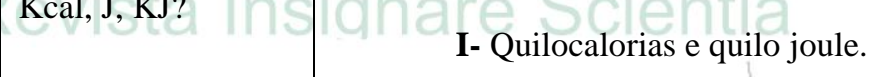

4. O alimento tem energia ou caloria? Justifique.
D- Os dois, pois caloria é a quantidade de energia que tem em um alimento.

E- Energia, que é medida em calorias.

F- O alimento tem energia e essa energia pode ser medida em caloria ou joule.

H- Possuem energia e essa energia pode ser medida pela caloria $=1$ cal é quantidade de calor necessárias para aumentar em $1^{\circ}$ Celsius a temperatura de 1 grama de água. 


\begin{tabular}{|c|c|}
\hline $\begin{array}{l}\text { 5. O que você } \\
\text { aprendeu com as } \\
\text { aulas? As } \\
\text { aprendizagens } \\
\text { foram importantes? } \\
\text { Justifique? }\end{array}$ & $\begin{array}{l}\text { A- Aprendi sobre calor, temperatura, a ler sobre os rótulos dos alimentos e } \\
\text { como ter uma vida alimentar mais saudável; } \\
\text { F- Unidade de medida de energia, como somar a caloria que cada } \\
\text { alimentos que consumimos, a quantidade calórica dos alimentos. e essa } \\
\text { aprendizagem foi muito importante pois na compressão de o que é energia. } \\
\text { I- Aprendi sobre a temperatura, energia, calor, caloria e, também sobre a } \\
\text { alimentação, as aulas foram muito importantes para conhecer mais sobre esses } \\
\text { assuntos e também para aprendizagem. }\end{array}$ \\
\hline $\begin{array}{l}\text { Faça sua } \\
\text { avaliação sobre as } \\
\text { aulas de química de } \\
\text { forma on-line, fale } \\
\text { como a professora } \\
\text { conduziu e dê }\end{array}$ & $\begin{array}{l}\text { A- A professora fez tudo de forma dinâmica e clara. Os únicos problemas } \\
\text { que enfrentamos foram os de conexão. } \\
\text { G- As aulas foram bem interessantes, com um conteúdo legal. A } \\
\text { professora interagiu muito bem conosco alunos, respondeu nossas dúvidas, além de } \\
\text { explicar de forma compreensível. Aulas excelentes! Minha sugestão é para que } \\
\text { tenha mais aulas como essas, eu adoraria participar! }\end{array}$ \\
\hline sugestões. & $\begin{array}{l}\text { I- As aulas foram ótimas eu amei, a professora explicou super bem } \\
\text { mesmo que de forma on-line deu pra entender certinho ela conduziu as aulas muito } \\
\text { bem, tirando todas as nossas dúvidas e respondendo todas as perguntas. }\end{array}$ \\
\hline
\end{tabular}

Fonte: elaborado pelos autores.

Constatamos que a perspectiva CTSA esteve presente em muitas respostas, destacamos as escritas do aluno A “[...] sim, sempre tive uma alimentação não muito saudável, por conta de não gostar de certos alimentos. As aulas que tivemos me fez refletir sobre meus hábitos alimentares, além de aprender química com a nossa rotina" e do aluno $\mathbf{H}$ “[...] sim, contribuiu muito para que eu entendesse que o alimento deve ser analisado antes de ser consumido, que devemos dar prioridade a alimentos naturais, fresco, que não devemos confiar totalmente em rótulos e marcas".

Com base nas respostas, verificamos que o ensino de química na perspectiva CTSA favoreceu a contextualização de conceitos, o aprendizado e a compreensão dos processos químicos do cotidiano. Dessa forma, podemos considerar a contextualização como sendo um "processo de ensino no qual os contextos sociais são objetos de estudo para transformar os conhecimentos prévios dos alunos em conceitos científicos, capazes de explicar os fenômenos da natureza que os rodeiam" (FILHO et al., 2015, p. 101).

Enfim, fica evidente diante dos dados analisados que as TIC contribuíram com a aprendizagem de química, por meio da investigação na perspectiva CTSA. Houve a sensibilização dos alunos por meio de suas reflexões e criticidade de suas respostas,

Recebido em: $27 / 08 / 2020$

Aceito em: $1 \% / 12 / 2020$ 
onde foram constatadas as percepções e relatos sobre seus próprios hábitos alimentares e consumo de alimentos.

\section{CONSIDERAÇÕES FINAIS}

Foi possível observar nesta pesquisa a importância das TIC como ferramentas pedagógicas. Realçamos a viabilidade das ferramentas utilizadas no desenvolvimento das atividades como instrumentos voltados para o ensino e a aprendizagem remota, o que ampliam as formas de acesso à educação.

Destacamos que as videoconferências (atividades síncronas) permitiram uma maior interação com os alunos, pois viabilizaram a socialização do conhecimento e o diálogo entre professor-aluno, aluno-aluno e aluno-professor. Já as outras ferramentas, como o WhasApp, complementaram a aprendizagem nos momentos assíncronos, pois foram úteis para esclarecimentos de dúvidas, envio e recebimento de atividades.

Enfatizamos a participação e interação dos alunos por meio de suas reflexões, criticidades, construções de conceitos, interações e sensibilizações durante a pesquisa, com um olhar especial durante este período de isolamento social.

Esperamos que a socialização desta prática de ensino contribua para o surgimento de novas práticas educacionais, que visam motivar os estudantes em aulas remotas através da contextualização dos conceitos de química.

\section{REFERÊNCIAS}

AKAHOSHI, L. H. Uma Análise de Materiais Instrucionais com Enfoque CTSA Produzidos por Professores em um Curso de Formação Continuada. Dissertação de Mestrado, Universidade de São Paulo, Programa de Pós-graduação Interunidades em Ensino de Ciências, São Paulo, 2012.

AQUINO, E. M. L. et al. Medidas de distanciamento social no controle da pandemia de COVID-19: potenciais impactos e desafios no Brasil. Revista Ciência e Saúde Coletiva. Vol. 25, Supl. 1.1, p. 2423-2446, Jun. 2020. Disponível em:< https://www.scielo.br/pdf/csc/v25s1/1413-8123-csc-25-s1-2423.pdf >. Acesso em: 27.08.2020.

BOGDAN, R.; BIKLEN, S. Investigação qualitativa em educação: uma introdução a teoria e aos métodos. Porto Editora, p.335, 1994.

Recebido em: $27 / 08 / 2020$

Aceito em: $1 \% / 12 / 2020$ 
BRASIL. Conselho Nacional de Educação. Ministério da Educação. Secretaria de Educação Básica. Base Nacional Comum Curricular: Ensino Médio. Brasília: MEC, 2018.

CHEVALLARD, Y. El análisis de las prácticas docentes en la teoría antropológica de lo didáctico. Recherches en Didactique des Mathématiques. Marseille, Vol. 19, n. 2, p. 221-266, 1999.

DOURADO, I. F. et al. Uso das TIC no Ensino de Ciências na Educação Básica: uma Experiência Didática. UNOPAR Científica Ciências Humanas e Educação, Londrina, Vol. 15, n. esp, p. 357-365, Dez. 2014.

FILHO, F. F. D. et al. Entendimento da abordagem CTSA no ensino de química e as dificuldades apontadas por professores de escolas públicas da cidade de Campina Grande -PB em inserir esse enfoque nas suas aulas. Revista Scientia Amazônia. Vol. 4, $\mathrm{n}^{\mathrm{o}} 2$, p. 100-106, 2015.

HALL, P. C. et al. Evolução da prevalência de infecção por COVID-19 no Rio Grande do Sul, Brasil: inquéritos sorológicos seriados. Revista Ciência e Saúde Coletiva, Vol. 25, $\mathrm{N}^{\mathrm{o}}$ 7, p. 2395-2401, Jun. 2020. Disponível em: < https://www.scielo.br/pdf/csc/v25s1/1413-8123-csc-25-s1-2395.pdf>. Acesso em: jul. 2020.

LUDKE, M.; ANDRÉ, M. E. D. A., Pesquisa em educação: abordagens qualitativas. São Paulo, E.P.U., 1986.

MARIN, J. C. et al. Tecnologias da Informação e Comunicação (TIC) no Ensino de Ciências e Teorias Educacionais: Estado do Conhecimento. \# Tear: Revista de Educação, Ciência e Tecnologia, V.8, n.2, p.1-18, 2019.

MATO GROSSO, Decreto $n^{\circ} 407$, de 16 de março de 2020. Dispõe sobre as medidas para enfrentamento da emergência de saúde pública de importância internacional decorrente do coronavírus (2019-nCoV) a serem adotados pelo Poder Executivo do Estado de Mato Grosso, e dá outras providências. Legislação do Estado de Mato Grosso, Cuiabá, 16 março de 2020. Disponível em: < http://app1.sefaz.mt.gov.br/Sistema/Legislacao/legislacaotribut.nsf/7c7b6a9347c50f550 32569140065ebbf/fa323b82aa0600ae0425852e003fb9d5?OpenDocument>. Acesso em: 21/07/2020.

MATO GROSSO, Decreto $\mathrm{n}^{\circ} 510$, de 03 de junho de 2020. Dispõe sobre a manutenção da suspensão das aulas presenciais no âmbito da rede pública de ensino, em decorrência da pandemia causada pelo agente novo coronavírus COVID-19, e dá outras providências. Legislação do Mato Grosso, Cuiabá, 03 junho 2020. em:

http://www.transparencia.mt.gov.br/documents/363605/14442674/DECRETO+N\%C2 $\% \mathrm{BA}+510 \% 2 \mathrm{C}+\mathrm{DE}+03+\mathrm{DE}+\mathrm{JUNHO}+\mathrm{DE}+2020$.pdf/99397c4e-9368-0146-cd32dc997ef49b48>. Acesso: 21/07/2020. 
MORAES, Roque. Análise de conteúdo. Revista Educação, Porto Alegre, v. 22, n37, p. 7-32, 1999.

OSÓRIO, T. R. et al. Investigação na Formação Inicial: concepções sobre as TIC e a Energia no Curso de Licenciatura em Ciências da Natureza. Revista Insignare Scientia. Vol. 2, n.2, Mai/Ago. p. 22-36, 2019. Disponível em: < https://periodicos.uffs.edu.br/index.php/RIS/article/view/10775/7199>. Acesso em: 21.07. 2020.

SANTOS, W. L. P. Educação CTS e Cidadania: Confluências e Diferenças. Revista de Educação em Ciências e Matemáticas, V. 9, nº17, p. 49-62, Jul/Dez 2012.

SANTOS, W. L. P. Contextualização no ensino de ciências por meio de temas CTS em uma perspectiva crítica. Revista Ciência e ensino. Vol. n especial,2007.

SANTOS, W. L. P; MORTIMER, E. F. Uma análise de pressupostos teóricos da abordagem C-T-S (Ciência-Tecnologia-Sociedade) no contexto da educação brasileira. Revista Ensaio Pesquisa em Educação em Ciências. Vol 02, no 2, p 110-113, Jul/Dez 2002.

SCHUHMACHER, V. R. N. et al. As barreiras da prática docente no uso das tecnologias de informação e comunicação, Ciência e Educação, Bauru, v. 23, n 3, p.563-576, 2017.

SULZBACHER, R., Contribuições da ferramenta tabela periódica interativa para o ensino de química em ciências. Revista Insignare Scientia. Vol. 2, n.3, Edição $\begin{array}{lllll}\text { Especial, } & \text { 255-261, 2019. Disponível } & \text { em: }\end{array}$ <https://periodicos.uffs.edu.br/index.php/RIS/article/view/11205/7272>. Acesso em: 27.07.2020.

ZANOTTO, R. L. et al. Ensino de conceitos químicos em um enfoque CTS a partir de saberes populares. Revista Ciência e Educação. Bauru, V. 22, n 3, p. 727-740, 2016. Disponível em:< https://www.scielo.br/pdf/ciedu/v22n3/1516-7313-ciedu-22-030727.pdf>. Acesso em: 22.07.2020.

Recebido em: $27 / 08 / 2020$

Aceito em: $1 \% / 12 / 2020$ 


\section{ANEXOS}

ANEXO I - QUESTIONÀRIO PRÉVIO

Nome:

Série: Turma:

1. Onde você observa a Ciência na sua vida? Cite exemplos e explique.

2. Na sua opinião a Escola ajuda a compreender a vida e a Ciência.

3. Os estudos na Escola mudaram a sua forma de ver o mundo a sua volta. Exemplifique.

4. Nas aulas de Ciências/Química você realizou atividades experimentais ou lúdicas? Quais?

5. Diferencie calor, caloria e energia.

6. O que é cal, Kcal, J, KJ?

7. O alimento tem energia ou caloria? Justifique.

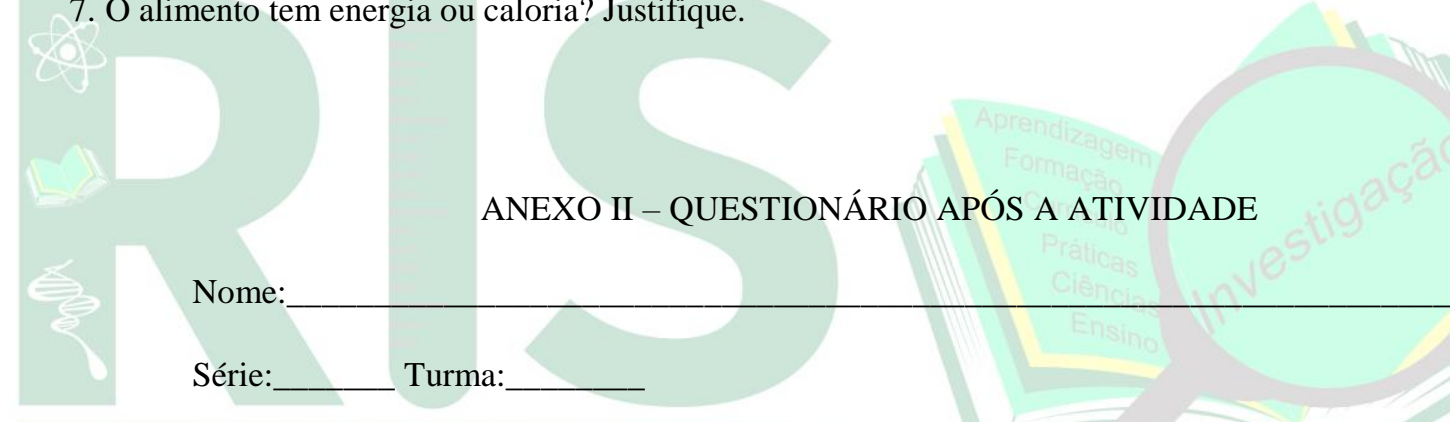

1. Responda sobre a atividade realizada:

A) Qual foi o assunto?

B) O que você ou seu grupo fez?

C) O que você aprendeu?

D) Estas atividades que você realizou contribuíram para você mudar sua opinião ou forma de compreender as coisas a sua volta? Explique.

2. Diferencie calor, caloria e energia.

3. O que é cal, Kcal, J, KJ?

4. O alimento tem energia ou caloria? Justifique.

5. O que você aprendeu com as aulas? As aprendizagens foram importantes? Justifique?

6. Faça sua avaliação sobre as aulas de química. Sobre como a professora conduz. Dê sugestões.

Recebido em: 27/08/2020

Aceito em: $1 \% / 12 / 2020$ 


\section{ANEXO III - ATIVIDADE PARA CASA 1 AULA}

\section{Atividade da Aula 01: Analisando o rótulo de diversas embalagens em casa}

Procedimento: Pedir para os estudantes verificar em suas casas diversos rótulos de alimentos como de molhos de tomate, refrigerantes, sucos, maionese, catchup, biscoitos e salgadinhos. Em seguida solicitar a leitura dos rótulos observando cada item e informação, principalmente aquelas relacionadas ao valor energético e calórico do alimento. Pedir para que o estudante separe três rótulos e responda em seu caderno as questões:

1. Observe nos rótulos escolhidos se está escrito: "valor energético", qual o significado dessa expressão?

2. O que significa as siglas KJ e Kcal? Elas têm alguma relação? Qual?

3. O que são calorias?

4. O termo valor energético e calorias contido nos rótulos têm o mesmo significado?

5. Escreva o nome do alimento e o valor energético que ele contém por porção.

6. Observe no final de cada rótulo o texto escrito em letras minúsculas:

“(*)\% Valores Diários de referência com base em uma dieta de $2000 \mathrm{Kcal}$ ou $8400 \mathrm{KJ}$.

Seus valores diários podem ser maiores ou menores, dependendo de suas necessidades energéticas". Responda:

O que significa "Valores diários de referência" e "necessidades energéticas"?

Ao finalizar a atividade, pedir para o estudante enviar pelo grupo de Whats App ou por e-mail para ser avaliada.

\section{ANEXO IV - ATIVIDADE PARA CASA 2 AULA}

\section{Atividade da Aula 02: Diário alimentar}

Procedimento: Durante três dias anotar (separadamente para cada dia) a rotina alimentar através das porções dos alimentos ingeridos no café da manhã, lanche, almoço, lanche e jantar. Calcular a quantidade de calorias ou energia consumidas em cada refeição, totalizado as calorias no final de cada dia. Para o cálculo das calorias de cada porção ingerida e anotada no diário, utilizar as referências calóricas presentes na a tabela de calorias dos alimentos mais servidos de A a Z disponível em: https://nowpix.com.br/emagrecer-tabela-de-calorias-completa/.

Ao finalizar a atividade, pedir para o estudante enviar pelo grupo de WhatsApp ou por e-mail para ser avaliada.

Recebido em: 27/08/2020

Aceito em: $1 \% / 12 / 2020$ 